\title{
Hepatic Protein Phosphotyrosine Phosphatase Dephosphorylation of Insulin and Epidermal Growth Factor Receptors in Normal and Alloxan Diabetic Rats
}

Philip A. Gruppuso, ${ }^{\star}$ Joan M. Boylan, ${ }^{\ddagger}$ Barry I. Posner, ${ }^{5}$ Robert Faure, ${ }^{5}$ and David L. Brautigan ${ }^{\star}$

${ }^{*}$ Department of Pediatrics, Rhode Island Hospital and Brown University, Providence, Rhode Island 02903; ${ }^{\ddagger}$ Section of Biochemistry, Division of Biology and Medicine, Brown University, Providence, Rhode Island 02912; and ${ }^{8}$ Department of Medicine,

Royal Victoria Hospital and McGill University, Montreal H3A 1A1, Canada

\begin{abstract}
Polypeptide hormone signal transmission by receptor tyrosine kinases requires the rapid reversal of tyrosine phosphorylation by protein phosphotyrosine phosphatases (PPTPases). We studied hepatic PPTPases in the rat with emphasis on acute and chronic regulation by insulin. PPTPase activity with artificial substrates $\left(\left(^{32} \mathrm{P}\right] \mathrm{T}\right.$ yr-reduced, carboxyamidomethylated, and maleylated lysozyme and ${ }^{32}$ P]Tyr-poly/glutamic acid:tyrosine] 4:1) was present in distinct membrane, cytoskeletal, and cytosolic fractions. These PPTPase activities were unaffected by alloxan diabetes. Acute administration of insulin to normal animals also did not change PPTPase activity in liver plasma membranes or endosomal membranes. Although alloxan diabetes did not affect PPTPase activity measured with artificial substrates or with epidermal growth factor receptors, a decrease in insulin receptor dephosphorylation was noted. Dephosphorylation of hepatic receptors from normal and diabetic rats by membrane PPTPase from control rats was similar. These results indicate that alloxan diabetes does not lead to a generalized effect on hepatic PPTPase activity, although a substrate-specific decrease in activity with the insulin receptor may occur. (J. Clin. Invest. 1990. 85:1754-1760.) protein phosphotyrosine phosphatases $\bullet$ hormone receptors $\bullet$ diabetes
\end{abstract}

\section{Introduction}

The binding of epidermal growth factor (EGF) ${ }^{1}(1)$ and insulin (2) to their respective receptors stimulates tyrosine kinase activity intrinsic to the receptors. This fact has led to the hypothesis that signal transmission for these and a number of other polypeptide hormones involves the phosphorylation of proteins on tyrosine. Thus far, receptor tyrosine kinases themselves represent the best characterized substrates for hormonestimulated tyrosine phosphorylation (for reviews, see references 3 and 4), although a number of other potential substrates

Address reprint requests to Dr. Philip A. Gruppuso, Division of Pediatric Endocrinology and Metabolism, Rhode Island Hospital, 593 Eddy Street, Providence, RI 02903.

Received for publication 2 December 1988 and in revised form 14 November 1989.

1. Abbreviations used in this paper: EGF, epidermal growth factor; polyEY, poly[glutamic acid:tyrosine] 4:1; PPTPase, protein phosphotyrosine phosphatase; RCAM-lysozyme, reduced, carboxyamidomethylated and maleylated lysozyme.

J. Clin. Invest.

(C) The American Society for Clinical Investigation, Inc.

$0021-9738 / 90 / 06 / 1754 / 07 \$ 2.00$

Volume 85, June 1990, 1754-1760 have been identified. Regardless of the nature of the substrates for tyrosine phosphorylation, assignment of a regulatory function to this process requires its reversal by protein phosphatases. Several such phosphatases have been purified from diverse sources, including rabbit kidney (5), human placenta (6, 7), and rat (8) and bovine (9) brain.

Discovery of the insulin-activated receptor tyrosine kinase led a number of investigators to study alterations in this activity in clinical and experimental states in which sensitivity to insulin is diminished. Type I and type II diabetes mellitus as well as obesity in nondiabetic subjects are known to be associated with insulin resistance (10-12). Decreased insulin receptor tyrosine kinase activity has been reported in adipocytes $(13,14)$, erythrocytes (15), skeletal muscle (16) and liver (17) from non-insulin-dependent diabetic subjects, and adipocytes from nondiabetic, obese individuals (14). Correlative animal studies exist (18-20), although at least two studies have failed to demonstrate decreased hepatic insulin receptor kinase activity in experimental diabetes in rats $(21,22)$. Given the reciprocal action of tyrosine kinases and phosphatases, we hypothesized that an increase in protein phosphotyrosine phosphatase (PPTPase) activity might contribute to the insulin resistance associated with decreased receptor-mediated tyrosine phosphorylation. Thus, we have undertaken the characterization of hepatic PPTPase activity in the rat, with emphasis on the effects of insulin.

\section{Methods}

Animal studies. The acute effects of insulin on hepatic PPTPase activities were studied by injecting female Sprague-Dawley rats (150-200 g; Charles River Ltd., St. Constant, Quebec, Canada) with $150 \mu \mathrm{g}$ insulin/100 $\mathrm{g}$ body weight via the jugular vein after an overnight fast. Rats were killed before and $30 \mathrm{~s}, 2 \mathrm{~min}$, and $10 \mathrm{~min}$ after injection. Plasma membrane and endosomal fractions were prepared from liver using sucrose density centrifugation (23).

Male Sprague-Dawley rats (Charles River Breeding Laboratories, Inc., Wilmington, MA) weighing 150-175 g were made diabetic by the intravenous administration of alloxan, $65 \mathrm{mg} / \mathrm{kg}$, after an overnight fast. Animals were killed $4 \mathrm{~d}$ after alloxan administration by decapitation. Severity of diabetes was ascertained by measurements of plasma glucose (model 23A glucose analyzer; Yellow Springs Instrument Co., Yellow Springs, $\mathrm{OH}$ ), immunoreactive insulin (using rat insulin standard; Amersham Corp., Arlington Heights, IL), and beta-hydroxybutyrate (24). A group of alloxan diabetic animals were treated with insulin (2 $U$ recombinant human insulin [Humulin; Eli Lilly and Co., Indianapolis, IN] i.p. every $12 \mathrm{~h}$ ) beginning $3 \mathrm{~d}$ after alloxan injection for $48 \mathrm{~h}$ before killing. Since alloxan diabetes was associated with a decreased rate of weight gain, three control animals were fasted for $48 \mathrm{~h}$ (ad lib water intake) before killing.

Unfractionated membrane preparations were made from individual, fresh livers by the method of Williams et al. (25) and diluted with $50 \mathrm{mM}$ Hepes, pH 7.5, to a concentration of $10 \mathrm{mg}$ protein $/ \mathrm{ml}$. Protein 
determinations were by the bicinchoninic acid method (BCA; Pierce Chemical Co., Rockford, IL) using BSA as standard.

The supernatants from membrane preparations were retained for measurement of soluble cytosolic activity. Detergent extracts of membrane preparations, referred to as the membrane fraction, were made by diluting 1 vol of the unfractionated membrane suspension with 1 vol $50 \mathrm{mM}$ Hepes, $\mathrm{pH} 7.4$, and $2 \%$ (wt/vol) Triton X-100. Insoluble material was collected by centrifugation at $40,000 \mathrm{~g}$ for $20 \mathrm{~min}$ and extracted with 0.5 vol $25 \mathrm{mM}$ Hepes, $\mathrm{pH} 7.4$, and $0.6 \mathrm{M} \mathrm{KCl}$. This second extract, clarified by centrifugation at $40,000 \mathrm{~g}$ for $20 \mathrm{~min}$, is referred to as the cytoskeletal fraction. Alloxan diabetes was not associated with altered membrane, cytoskeletal, or cytosolic protein contents.

PPTPase assays. PPTPase activity was measured as the release of ${ }^{32} \mathrm{P}$ from substrates phosphorylated on tyrosine (5). Assays were carried out in the presence of $1 \mathrm{mM}$ EDTA and $15 \mathrm{mM}$ 2-mercaptoethanol. Reduced, carboxyamidomethylated and maleylated lysozyme (RCAM-lysozyme) and poly[glutamic acid:tyrosine] 4:1 (polyEY) were labeled on tyrosine using partially purified human placental insulin receptor tyrosine kinase as described by Tonks et al. (6). Dephosphorylation of $\left[{ }^{32} \mathrm{P}\right] \mathrm{Tyr}-$ polyEY and $\left[{ }^{32} \mathrm{P}\right] \mathrm{Tyr}-\mathrm{RCAM}-\mathrm{lys}$ sozyme was measured at a final substrate concentration of $1 \mu \mathrm{M}$. PPTPase activities are reported as nanomoles or picomoles of ${ }^{32} \mathrm{P}$ released per minute.

Receptor preparation, binding, and autophosphorylation. Rat liver insulin and EGF receptors were prepared for use as phosphatase substrates as follows. Rat liver membranes were extracted with $1 \%$ Triton $\mathrm{X}-100$. The extract (32-91 mg protein in $2.5-4.0 \mathrm{ml}$ ) was applied to a 10-ml column of wheat germ lectin-Sepharose (Pharmacia Fine Chemicals, Piscataway, NJ) and unbound proteins were applied a second time. The column was washed with $250 \mathrm{ml}$ of $40 \mathrm{mM}$ imidazole$\mathrm{HCl}, 0.5 \mathrm{M} \mathrm{NaCl}, 10 \%$ glycerol, and $0.05 \%$ Triton X-100, pH 7.2. Receptors were then eluted with the same buffer containing $0.3 \mathrm{M}$ $\mathrm{N}$-acetyl glucosamine. Fractions that bound ${ }^{125} \mathrm{I}$-insulin were pooled. This same pool contained EGF receptors.

For determination of the specific binding of insulin in lectin-purified preparations and in solubilized plasma membrane and endosomal fractions, $50 \mu$ l receptor was incubated with ${ }^{125}$ I-human insulin $(40,000 \mathrm{cpm}, 100 \mu \mathrm{l}$; New England Nuclear, Boston, MA) for $1 \mathrm{~h}$ at $22^{\circ} \mathrm{C}$. Bound insulin was separated from unbound insulin with the addition of $50 \mu \mathrm{l} 2 \%$ bovine gamma globulin and $1.5 \mathrm{ml} 15 \%$ polyethylene glycol followed by centrifugation (26).

Receptor autophosphorylation was accomplished by incubating receptor preparations $(40 \mu \mathrm{l})$ with hormones $\left(20 \mu \mathrm{l}, 3 \times 10^{-7} \mathrm{M}\right.$ insulin and EGF, final concentrations) overnight at $4^{\circ} \mathrm{C}$. Receptor activation was followed by the addition of $15 \mu$ l containing $6.75 \mu \mathrm{Ci}$ [gamma$\left.{ }^{32} \mathrm{P}\right] \mathrm{ATP}, 50 \mu \mathrm{M}$ ATP, and $25 \mathrm{mM} \mathrm{MnCl}_{2}$. Incubation at $4^{\circ} \mathrm{C}$ proceeded for $30 \mathrm{~min}$ and was carried out in the absence of phosphatase inhibitors. Receptor phosphorylation was terminated by the addition of 2-mercaptoethanol (15 mM, final concentration) and EDTA (6 $\mathrm{mM}$, final concentration) in $15 \mu \mathrm{l}$.

Receptor dephosphorylation was initiated by the addition of $8 \mu \mathrm{l}$ PPTPase. An additional 2- $\mu$ l volume was reserved for the addition of phosphatase inhibitors or buffer as control. The reaction proceded at $37^{\circ} \mathrm{C}$ and was terminated by the addition of $5 \times$ gel electrophoresis sample buffer containing $50 \mathrm{mM}$ ATP, $10 \%$ dodecyl sulfate, and $0.5 \mathrm{M}$ dithiothreitol, followed by a 10-min incubation in a boiling water bath. Analysis was by electrophoresis in $7.5 \%$ polyacrylamide gels followed by exposure of the dried gel to Kodak XAR-5 film at $-70^{\circ} \mathrm{C}$ in the presence of intensifying screens. Radiolabeled bands were quantified with a scanning densitometer (model 300S; Hoefer Scientific Instruments, San Francisco, CA) connected to a Hewlett-Packard integrator (model 3390A). Densitometric scanning was reported as the mean of triplicate determinations.

\section{Results}

Characterization of rat liver particulate PPTPase activities. Preliminary studies showed that $\sim 60-70 \%$ of total hepatic
PPTPase activity measured with [ $\left.{ }^{32} \mathrm{P}\right] \mathrm{T}$ yr-RCAM-lysozyme was soluble. Most of the particulate activity $(80 \%)$ could be extracted with $1 \%$ Triton X-100. The remaining particulate activity (20\%) was soluble in $0.6 \mathrm{M} \mathrm{KCl}$. Further studies showed that extraction with Triton X-100 a second time did not diminish the amount of activity that could be obtained by extraction of the detergent-insoluble proteins with $0.6 \mathrm{M} \mathrm{KCl}$. Furthermore, reversing the order of extraction ( $\mathrm{KCl}$ followed by detergent) did not significantly alter the yield of activity in the two fractions. Thus, we concluded that particulate PPTPase was localized to distinct membrane (soluble in Triton X-100) and cytoskeletal (soluble in $0.6 \mathrm{M} \mathrm{KCl}$ ) fractions. Initial studies were aimed at characterizing activities in these two fractions as well as the soluble fraction to determine whether these activities should be attributed to more than one enzyme.

Membrane and cytoskeleton PPTPase measured with [22 P]Tyr-RCAM-lysozyme displayed neutral pH optima (not shown). They displayed similar sensitivity to the PPTPase inhibitors vanadate and zinc $\left(\mathrm{IC}_{50} \sim 250 \mu \mathrm{M}\right.$, data not shown). Cytosolic, membrane, and cytoskeleton PPTPase measured with $\left[{ }^{32} \mathrm{P}\right] \mathrm{Tyr}-\mathrm{RCAM}$-lysozyme were similar with regard to inhibition by polyEY, dodecyl sulfate, or heat inactivation at $57^{\circ} \mathrm{C}$ (Fig. 1).

Because PPTPase measurements made with [ $\left.{ }^{32} \mathrm{P}\right] \mathrm{Tyr}$ polyEY consistently resulted in higher specific activities than those done with [ ${ }^{32}$ P]Tyr-RCAM-lysozyme (see below), we investigated the possibility of a second type of PPTPase specifcally active against $\left[{ }^{32} \mathrm{P}\right] \mathrm{Tyr}$-polyEY. Membrane PPTPase activities measured with both substrates were indistinguishable based on inhibition by vanadate, denaturation by dodecyl sulfate, and inactivation at $45^{\circ} \mathrm{C}$ (Fig. 2). Likewise, no differences were observed using cytoskeletal PPTPase (not shown). We concluded that these substrates were reactive with one PPTPase, or with catalytic proteins with nearly identical properties.

During our initial studies we observed that soluble PPTPase was liberated from frozen membrane preparations upon thawing. We therefore performed an experiment to ascertain if soluble PPTPase could be released from membranes by proteolysis. Particulate membranes were treated with trypsin (Fig. 3) and the soluble proteins recovered after centrifugation were assayed for PPTPase activity. Trypsin

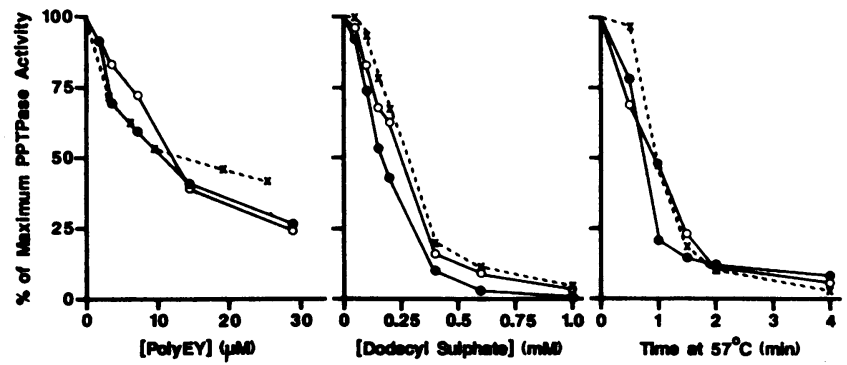

Figure 1. Comparison of particulate and soluble PPTPase activities. Activity was measured in membrane (๑), cytoskeleton (0), and cytosolic $(x)$ fractions using $\left[{ }^{32} \mathrm{P}\right]$ Tyr-RCAM-lysozyme. Heat inactivation at $57^{\circ} \mathrm{C}$ was measured by adding enzyme to prewarmed tubes. Heating was stopped at the designated times by diluting an aliquot of the enzyme in ice-cold assay buffer (1:50 for the membrane fraction, 1:20 for the cytoskeleton fraction, and 1:10 for the cytosolic fraction). 


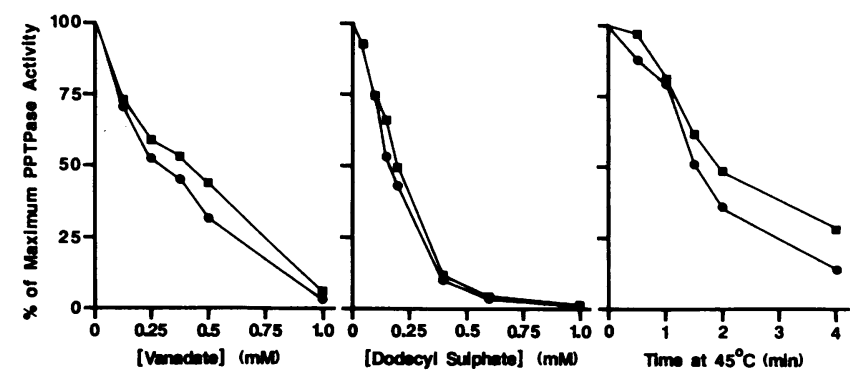

Figure 2. Comparison of membrane PPTPase activities measured with $\left[{ }^{32} \mathrm{P}\right] \mathrm{Tyr}-\mathrm{polyEY}(\bullet)$ and $\left[{ }^{32} \mathrm{P}\right] \mathrm{Tyr}-\mathrm{RCAM}$-lysozyme $(\boldsymbol{(})$. Heat inactivation at $45^{\circ} \mathrm{C}$ was determined as in Fig. 1.

treatment of membranes resulted in time-dependent release of a soluble PPTPase. Conversely, exposure of soluble PPTPase to trypsin led to loss of activity (Fig. 3). The results shown in the figure were replicated in a second, independent experiment.

Acute effects of insulin administration on PPTPase activities. The intravenous injection of insulin into rats (Fig. 4) resulted in an increase in insulin binding in hepatic endosomal fractions within 2 min and a concomitant decrease in plasma membrane insulin binding. In contrast, PPTPase activity did not change significantly (as determined by analysis of variance) in either plasma membrane or endosomal fractions after insulin administration. Of note, PPTPase specific activities were similar in the two membrane fractions.

Effects of alloxan diabetes on PPTPase activities. The injection of alloxan resulted in hyperglycemia $(597 \pm 89 \mathrm{mg} / \mathrm{dl}$ [mean \pm SD] vs. $189 \pm 29$ in control animals) and relative insulinopenia (median, $0.2 \mathrm{ng} / \mathrm{ml}$ [range, $0.1-0.9$ ] vs. 2.8 [1.8-5.1] in control animals). Diabetic animals had elevated plasma beta-hydroxybutyrate concentrations $(0.69 \mathrm{mM}[0.57-4.37])$ compared with control animals $(0.22 \mathrm{mM}$ [0.18-0.25]); levels were insufficient to produce acidosis. The overall well-being of diabetic animals was confirmed by their ability to gain weight after alloxan administration ( $7.8 \pm 4.0$ vs. $11.8 \pm 1.2 \mathrm{~g} / \mathrm{d}$ in control animals). Insulin treatment of alloxan diabetes resulted in restoration of normal plasma glucose $(100 \pm 17 \mathrm{mg} / \mathrm{dl})$ and beta-hydroxybutyrate $(0.22 \mathrm{mM}[0.10-0.33])$ concentrations.

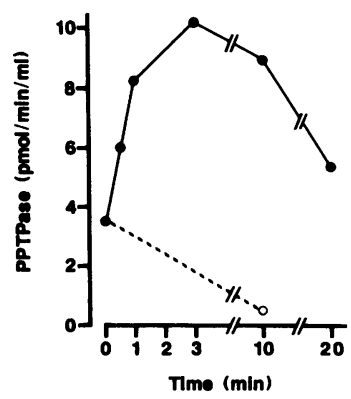

Figure 3. Generation of soluble PPTPase activity by treatment of particulate membranes with trypsin. A membrane preparation at $1 \mathrm{mg} / \mathrm{ml}$ protein content was incubated with trypsin at a final concentration of 4 $\mu \mathrm{g} / \mathrm{ml}$. Proteolysis was stopped at the designated times by transferring $80 \mu \mathrm{l}$ of the mixture to a tube on ice containing $0.4 \mu \mathrm{g}$ lima bean trypsin inhibitor. The membranes were collected by centrifugation in a microfuge for $10 \mathrm{~min}$ at $4^{\circ} \mathrm{C}$. The

supernatant was assayed directly for PPTPase activity using $\left.{ }^{32} \mathrm{P}\right] \mathrm{Tyr}-$ RCAM-lysozyme (๑). Treatment of the membrane supernatant from $t=0$ with trypsin for $10 \mathrm{~min}$ resulted in loss, rather than generation, of activity (0). Particulate membranes recovered after trypsin treatment were also assayed for PPTPase. Activity was totally depleted by $5 \mathrm{~min}$.

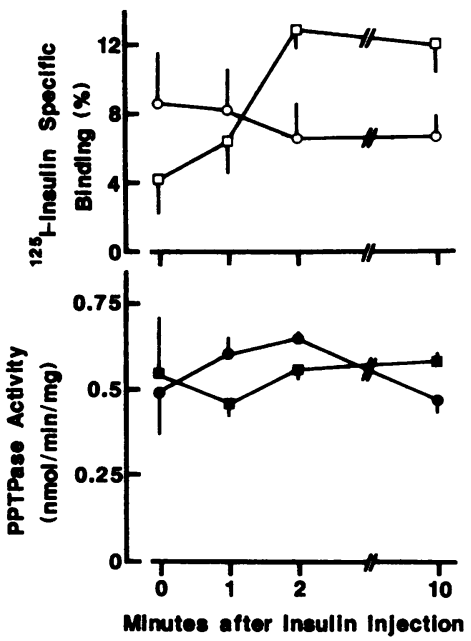

Figure 4. Acute effects of insulin administration on hepatic membrane-associated PPTPase activity. Rat liver was obtained at the designated times after the intravenous administration of insulin. Plasma membranes (circles) and endosomal membranes (squares) were prepared for the measurement of insulin binding (open symbols) and PPTPase activity (closed symbols). Insulin binding was corrected for protein content to allow comparison between preparations. PPTPase activity was measured using $\left[{ }^{32} \mathrm{P}\right]$ Tyr-RCAM-lysozyme. Measurements represent mean $\pm \mathrm{SE}$ for three experiments.

Alloxan diabetes did not alter soluble, membrane, or cytoskeletal PPTPase activity measured with [ $\left.{ }^{32} \mathrm{P}\right] \mathrm{Tyr}-\mathrm{RCAM}-$ lysozyme or [ $\left.{ }^{32} \mathrm{P}\right] \mathrm{T}$ yr-polyEY (Fig. 5). Significantly higher specific activities were obtained in all fractions using the latter substrate. To study the significance of the decreased rate of weight gain in diabetic animals, we measured PPTPase activity in three control rats fasted for $48 \mathrm{~h}$ before killing. Fasting did not alter PPTPase specific activity measured with both substrates in any of the three liver fractions (Fig. 5).

To further investigate a possible effect of alloxan diabetes on PPTPase activities, kinetic analyses were performed using [ $\left.{ }^{32} \mathrm{P}\right] \mathrm{Tyr}-\mathrm{RCAM}$-lysozyme. Double-reciprocal analysis of substrate concentration versus rate of hydrolysis (not shown) demonstrated that the $K_{\mathrm{m}}$ for substrate was unchanged in alloxan diabetes for membrane $(382 \pm 46 \mathrm{nM}$ [mean \pm SD] vs. $423 \pm 75 \mathrm{nM}$ in controls) and cytoskeleton (702 $\pm 358 \mathrm{nM}$ vs. $629 \pm 337 \mathrm{nM}$ in controls). In all cases these analyses were linear, indicating reactions with a single substrate affinity.

Studies on PPTPase activities with insulin and EGF receptors as substrates. The aforementioned studies were performed

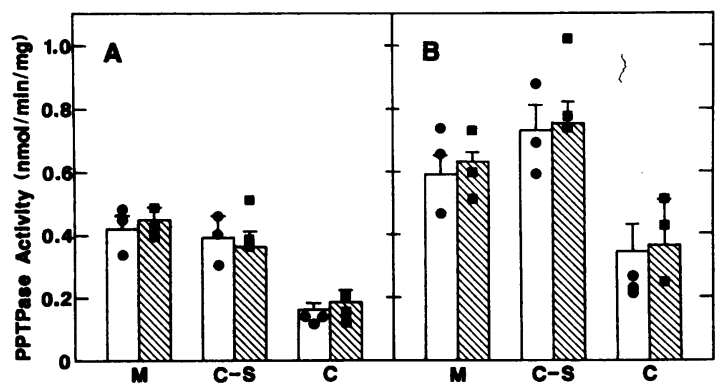

Figure 5. Hepatic PPTPase activity in control and alloxan-diabetic animals. Activity was determined in membrane $(M)$, cytoskeleton $(C-S)$, and cytosolic $(C)$ fractions from control animals $(n=6$, open bars), alloxan-diabetic animals ( $n=6$, hatched bars), insulin-treated alloxan-diabetic animals (circles), and animals fasted for $48 \mathrm{~h}$ (squares). PPTPase activity was measured using both [ $\left.{ }^{32} \mathrm{P}\right] \mathrm{Tyr}-$ lysozyme $(A)$ and $\left.{ }^{32} \mathrm{P}\right]$ Tyr-RCAM-polyEY $(B)$. Error bars represent $1 \mathrm{SD}$. 
using artificial substrates for PPTPase measurements. Such artificial substrates can be prepared in sufficiently high concentrations to allow determination of reaction rates. Nonetheless, interpretation of such measurements is limited by the nonphysiologic nature of these substrates. We therefore sought to perform correlative studies using autophosphorylated rat liver insulin and EGF receptors as physiologic substrates. Autophosphorylated receptors were identified as proteins with $M_{\mathrm{r}}$ $=170,000$ (EGF receptor) and 95,000 (beta subunit of the insulin receptor), which were phosphorylated in response to hormones (see Methods). Insulin receptor phosphorylation was stimulated 15 to 20-fold by insulin, whereas EGF receptor phosphorylation was stimulated approximately 5-fold.

Our initial studies demonstrated that PPTPase activity against autophosphorylated receptors had characteristics in common with activity measured with artificial substrates. Both had an absolute requirement for reducing agent (15 mM 2-mercaptoethanol); in its absence, no activity could be detected. Both activities were preserved in the presence of EDTA and were fully inhibited by micromolar concentrations of vanadate.

To correlate PPTPase activities measured with $\left[{ }^{32} \mathrm{P}\right] \mathrm{Tyr}-$ RCAM-lysozyme and receptors, hepatic PPTPase was subjected to gel filtration chromatography (Fig. 6). A liver homogenate was extracted with $1 \%$ Triton X-100. The soluble proteins were concentrated $\sim 10$-fold by vacuum dialysis and 1 $\mathrm{ml}$ was applied to a $1.5 \times 33-\mathrm{cm}$ column of Ultrogel AcA 44

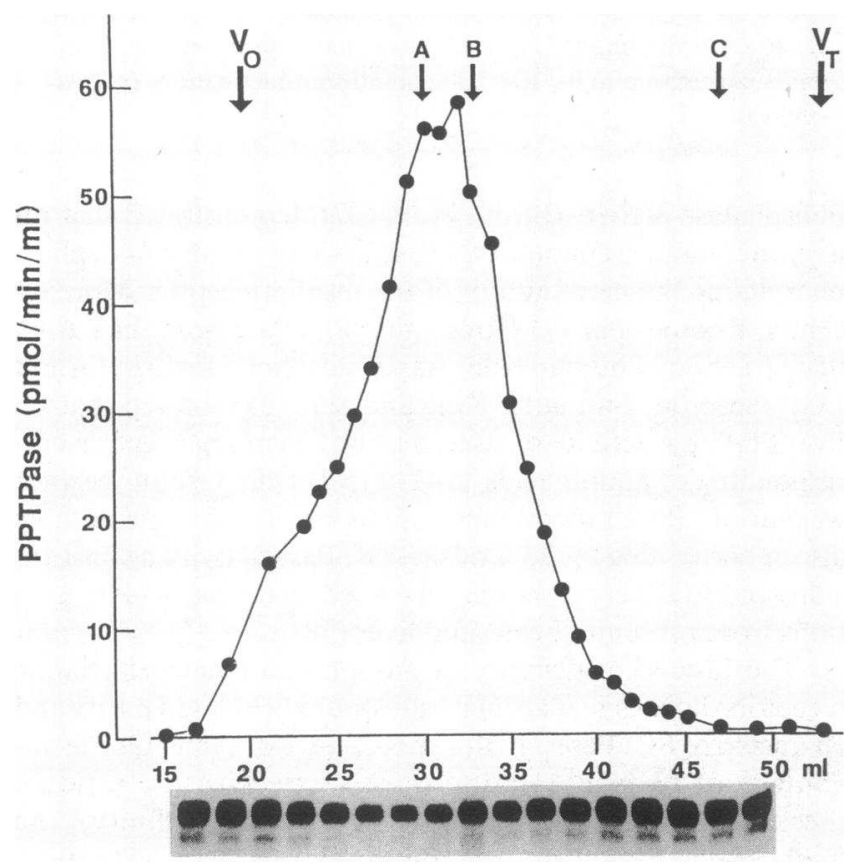

Figure 6. Gel filtration chromatography of membrane-associated PPTPase. A concentrated liver extract was prepared and applied to a column of Ultrogel AcA 44 as described in Results. PPTPase activity, measured with [ $\left.{ }^{32} \mathrm{P}\right] \mathrm{Tyr}-\mathrm{RCAM}-\mathrm{lysozyme}$, is shown in the graph. The autoradiogram at the bottom of the figure shows the ability of corresponding fractions to dephosphorylate an autophosphorylated EGF receptor preparation from a normal rat. Arrows at the top of the figure denote the positions of the following: $V_{0}$, void volume; $A$, BSA $\left(M_{\mathrm{r}}=67,000\right) ; B$, ovalbumin $\left(M_{\mathrm{r}}=43,000\right) ; C$, chymotrypsinogen $\mathrm{A}\left(M_{\mathrm{r}}=25,000\right)$; and $V_{T}$, total column volume. equilibrated in $20 \mathrm{mM}$ Hepes, pH 7.4, 10\% glycerol, $50 \mathrm{mM}$ $\mathrm{NaCl}$, and $30 \mathrm{mM}$ 2-mercaptoethanol. PPTPase activity measured with [ $\left.{ }^{32} \mathrm{P}\right] \mathrm{Tyr}-\mathrm{RCAM}$-lysozyme eluted as a broad peak with maximal activity centered at $M_{\mathrm{r}} \sim 55,000$. The fractions containing PPTPase activity with [ $\left.{ }^{32} \mathrm{P}\right] \mathrm{T}$ yr-RCAM-lysozyme were also active against autophosphorylated EGF receptors (Fig. 6). These same fractions had activity with insulin receptors (not shown). No [ $\left.{ }^{32} \mathrm{P}\right] \mathrm{Tyr}-\mathrm{RCAM}$-lysozyme, EGF receptor, or insulin receptor dephosphorylation was seen in fractions coincident with the elution of chymotrypsinogen $\mathrm{A}\left(M_{\mathrm{r}}\right.$ $=25,000)$. Other studies have found PPTPases of this size with activity against synthetic peptides corresponding to portions of the insulin receptor (see below).

Membrane extracts from control and alloxan diabetic rats contained PPTPase activity capable of dephosphorylating hepatic insulin and EGF receptors from normal rats (Fig. 7). Using membrane PPTPase from normal animals, the extent of insulin receptor dephosphorylation was consistently greater than EGF receptor dephosphorylation (Fig. 7. left). In contrast, membrane PPTPase from diabetic animals dephosphorylated both receptors similarly (Fig. 7, right). EGF receptor dephosphorylation was similar in the two groups, thereby indicating a decrease in the extent of insulin receptor dephosphorylation with PPTPase from diabetic animals. Similar results were obtained in replicate studies using three additional control and diabetic membrane extracts (not shown).

In addition, sensitivity of receptor dephosphorylation to polyEY was studied. As shown in Fig. 7, EGF receptor dephosphorylation in all cases was at least partially inhibited by the addition of $100 \mu \mathrm{M}$ polyEY. In contrast, insulin receptor dephosphorylation by normal or diabetic extract PPTPase was not sensitive to inhibition by polyEY. Dose response of the inhibition of EGF receptor dephosphorylation (not shown) indicated half maximal inhibition at $\sim 10-30 \mu \mathrm{M}$ polyEY.

To complement these studies on alterations in receptor PPTPases in alloxan diabetes, we examined the possibility that alloxan diabetes might alter receptor dephosphorylation via effects on the receptors themselves. Studies similar to those shown in Fig. 7 were carried out using PPTPase extracted from control membranes to dephosphorylate insulin and EGF receptors from two control and two alloxan diabetic animals. Results (not shown) demonstrated that alloxan diabetes did not alter the susceptibility of EGF or insulin receptors to dephosphorylation by control PPTPase. Finally, EGF and insulin receptors from control and alloxan diabetic animals were dephosphorylated similarly by PPTPase from a diabetic animal.

\section{Discussion}

Until recently the only physiologic substrates for the insulin and EGF receptor kinases that had defined roles were the receptors themselves. Currently, a number of potential substrates for receptor-associated tyrosine kinases have been described, including several proteins without assigned functions (27-31), lipocortin (32), a protein kinase oncogene product (33), and an EGF-activated phospholipase (34). Studies on PPTPases have been limited by the availability of physiologic tyrosine kinase substrates. PPTPases that can dephosphorylate insulin and/or EGF receptors have been purified from human placenta $(7,35)$. In these studies, monitoring of activity during 


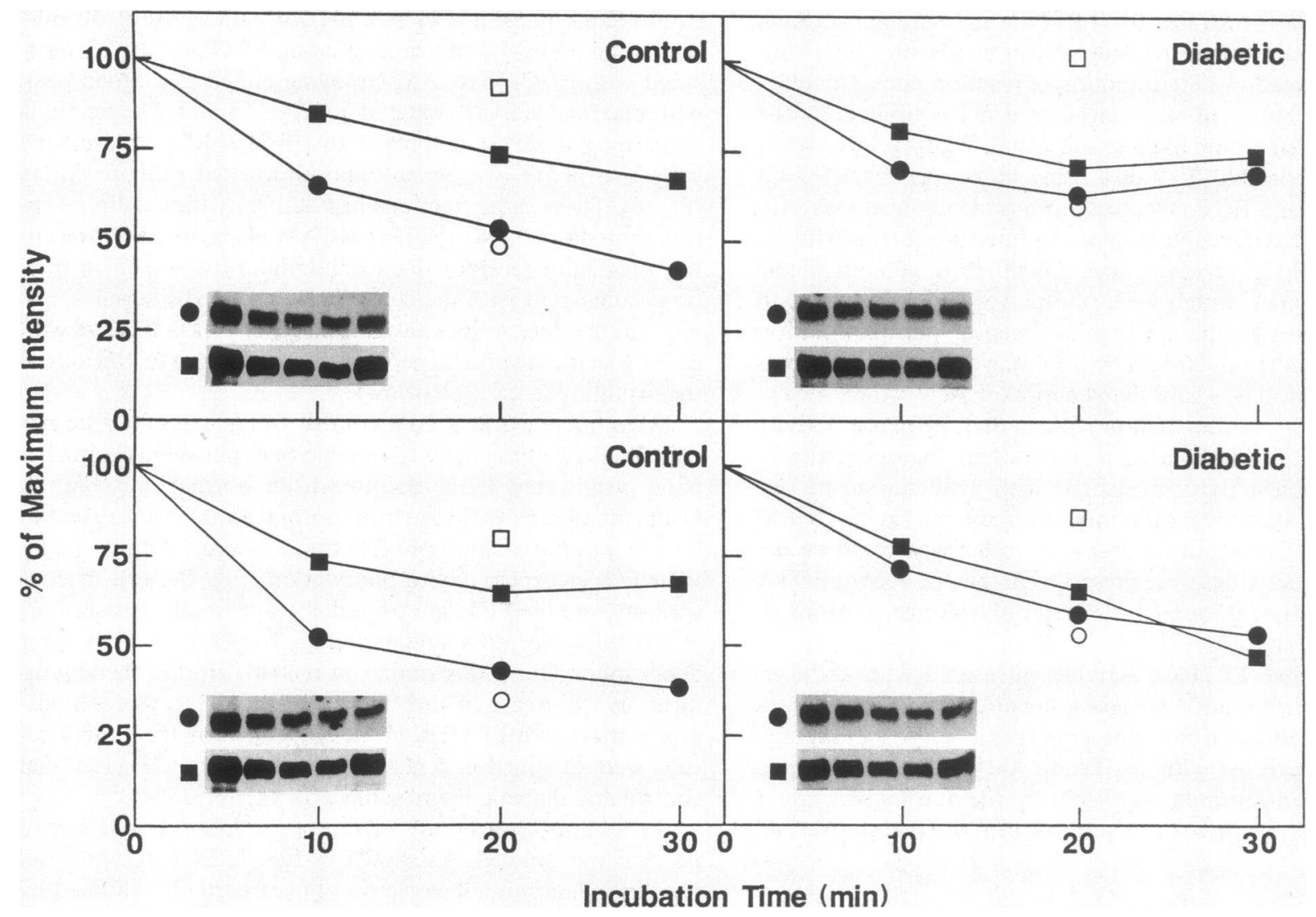

Figure 7. Dephosphorylation of hepatic insulin receptor beta subunit (circles) and EGF receptors (squares) by liver membrane extracts from control and alloxan-diabetic rats. Lanes (from left to right) in the autoradiograms correspond to 0-, 10-, 20-, and 30-min incubations (closed symbols) and 20-min incubation in the presence of $100 \mu \mathrm{M}$ polyEY (open symbols).

purification using artificial substrates yielded enzymes active against the physiologic receptor substrates.

In these studies we have attempted to characterize particulate and soluble hepatic PPTPases using artificial substrates. Our results are most consistent with a single class of PPTPase that dephosphorylates both $\left[{ }^{32} \mathrm{P}\right]$ Tyr-RCAM-lysozyme and $\left[{ }^{32} \mathrm{P}\right]$ Tyr-polyEY. This activity is characterized by well-recognized functional criteria; i.e., neutral $\mathrm{pH}$ optimum and sensitivity to inhibition by zinc, vanadate, and polyEY. Linear double-reciprocal analyses of enzyme kinetics and inhibition/inactivation data are most consistent with a single catalytic moiety.

Hepatic PPTPase is distributed in distinct membrane and cytoskeletal fractions as well as the soluble fraction. Our data indicate that the latter may be partly derived from particulate fractions by limited proteolysis. Furthermore, membrane-associated PPTPase was distributed in both plasma membrane and endosomal fractions, consistent with accessibility to phosphorylated receptors during the process of ligand-stimulated receptor internalization.

We have concentrated our efforts on the measurement of particulate PPTPase activities for several reasons. First is the observation that soluble PPTPase activity can be generated by proteolysis of rabbit kidney membranes (36), a finding that we have confirmed in rat liver. Second, the presence of PPTPase activity in the membrane and cytoskeleton might result in colocalization of tyrosine kinases, their substrates, and protein phosphatase activity. Strout et al. (37) demonstrated that rat liver membranes contain PPTPase activity capable of dephosphorylating the beta subunit of the insulin receptor. More recently, Roome et al. (7) showed that PPTPase from the particulate fraction of human placenta dephosphorylates insulin and EGF receptors. Similarly, King and Sale (38) showed that rat liver PPTPase activity measured using a synthetic peptide corresponding to amino acids $1142-1153$ of the insulin receptor was mostly $(80 \%)$ membrane associated. These same authors also reported that $\sim 75 \%$ of the PPTPase activity against insulin and EGF receptors was recovered in the particulate fractions from rat brain, heart, and liver (38).

The limited availability of autophosphorylated hormone receptors dictates that artificial substrates be used to purify and characterize PPTPases. $\left[{ }^{32}\right.$ P]Tyr-RCAM-lysozyme has the advantage of phosphorylation on a single tyrosine residue, thereby avoiding multiple sites with varying affinity. The $\left.{ }^{32} \mathrm{P}\right]$ Tyr-polyEY substrate is unusual in that hepatic particulate PPTPase activity is inhibited by micromolar concentrations of polyEY. In fact, we used this substrate in an attempt to measure a polyEY-insensitive enzyme. Tonks et al. (35) characterized two protein tyrosine phosphatases from human placenta that were most readily distinguished by sensitivity to polyEY. PPTPase $1 \mathrm{~A}$ and $1 \mathrm{~B}$ were inhibited $50 \%$ by $\sim 4 \mu \mathrm{M}$ and $50 \mathrm{nM}$ polyEY, respectively. The sensitivity of unpurified rat liver particulate and soluble PPTPase activities measured with [ $\left.{ }^{32} \mathrm{P}\right] \mathrm{Tyr}-\mathrm{RCAM}$-lysozyme substrate ( $50 \%$ inhibition with 
$\sim 10 \mu \mathrm{M}$ polyEY) is sufficient to characterize it as polyEY sensitive, but not to permit comparison with the purified placental enzymes.

Several studies have been published recently that use synthetic peptides phosphorylated on tyrosine to monitor PPTPase activity. The primary structure for these peptides has been derived from the structure of autophosphorylated tyrosine kinases (either the insulin receptor $[38,39]$ or the oncogene pp60src [40]). Sparks and Brautigan (41) reported that cytosolic rabbit kidney PPTPases could dephosphorylate serum albumin, casein, and myosin light chains, while two peptide substrates $\left(\left[\mathrm{Val}^{5}\right]\right.$ angiotensin and the pp60src-derived peptide noted above) were not substrates for this enzyme.

Examination of the recent report by Myerovitch et al. (39) indicates further the need to be cautious in interpreting PPTPase measurements using artificial substrates. These authors measured PPTPase activity in normal and diabetic rats with a peptide corresponding to residues $1142-1153$ of the insulin receptor. Their results showed zinc-sensitive activities in rat liver membrane preparations of $\sim 2-3 \mathrm{pmol} / \mathrm{min}$ per mg protein (compared with $\sim 400 \mathrm{pmol} / \mathrm{min}$ per $\mathrm{mg}$ measured in the present study with [ $\left.{ }^{32} \mathrm{P}\right] \mathrm{Ty}$-RCAM-lysozyme). While no change in particulate PPTPase activity was seen with streptozotocin diabetes, a reproducible increase of $30-80 \%$ in soluble activity was seen. In addition, it was demonstrated that this soluble activity resided in an enzyme with an $M_{\mathrm{r}}$ of $20,000-25,000$ based on gel filtration chromatography. However, our own gel filtration analysis of PPTPase activity against autophosphorylated hormone receptors indicates no activity in the range of $M_{\mathrm{r}}=25,000$.

In an attempt to correlate PPTPase activity with artificial substrates and results using physiologic substrates (insulin and EGF receptors) we found that activity against the two receptor substrates differed in sensitivity to inhibition by polyEY and effects of alloxan diabetes. This result might be interpreted as indicating that distinct enzymes dephosphorylate the two receptor substrates. It also raises the possibility that different enzymes are measured using the artificial versus physiologic substrates. Since initiating these studies we have undertaken purification of rat hepatic PPTPase using [ $\left.{ }^{32} \mathrm{P}\right]$ Tyr-RCAMlysozyme to monitor activity (manuscript in preparation). Affinity chromatography on polylysine agarose yields two peaks of activity. Both are fully inhibited by micromolar concentrations of polyEY. However, both PPTPases are capable of dephosphorylating insulin and EGF receptors and only activity against the latter is inhibited by polyEY. Furthermore, the enzymes maintain an apparent $M_{\mathrm{r}}$ of 50,000-60,000 throughout purification. This finding supports the identity of these enzymes with the major insulin and EGF receptor PPTPases in rat liver membranes. The results of the studies presented herein are therefore interpreted as indicating that $(a)$ inhibition by polyEY is substrate dependent, and $(b)$ PPTPases with $M_{\mathrm{r}}$ 's of 50,000-60,000 are capable of dephosphorylating both the artificial and physiologic substrates used in the present study.

An additional finding still demands explanation, however. The difference in the effects of alloxan diabetes on dephosphorylation of insulin versus EGF receptors must be interpreted as indicating distinct PPTPases that are substrate specific and independently regulated. This situation is reminiscent of the relationship between glycogen synthase phosphatase and phosphorylase phosphatase. These glycogenassociated phosphatases are both forms of type 1 protein phosphatase (42). However, alloxan diabetes in the rat results in a marked decrease in synthase phosphatase activity with no effect on phosphorylase phosphatase activity $(43,44)$. It is unknown whether substrate specificity for type 1 protein phosphatase is dependent on associated regulatory proteins or posttranslational modification of the catalytic subunits. Similarly, the relationship between PPTPases that dephosphorylate insulin and EGF receptors will have to await isolation and characterization of catalytic and regulatory subunits.

The present studies also should be interpreted in relation to our original hypothesis: an increase in PPTPase activity will contribute to the insulin resistance seen in states associated with decreased insulin receptor kinase activity. Our data indicate that, in the specific case of experimental diabetes in the rat, no generalized alteration in PPTPase activity occurs. Indeed, studies with autophosphorylated receptors indicate that a decrease in insulin receptor dephosphorylation may occur. Most importantly, the constitutive expression of hepatic PPTPase activity after acute insulin administration and the distribution of PPTPase activity in both cell surface and intracellular membranes suggest a primary regulatory role for receptor-associated tyrosine kinases.

\section{Acknowledgments}

The authors thank Beth Smiley and Patricia Carter for their assistance in the performance of these studies.

This work was supported by a Juvenile Diabetes Foundation research grant (to Dr. Gruppuso), National Institutes of Health grant HD-24455 (to Dr. Gruppuso), National Institutes of Health grants GM-35266 and HD-11343 (to Dr. Brautigan), and a grant from the Medical Research Council of Canada (to Dr. Posner).

\section{References}

1. Carpenter, G. 1987. Receptors for epidermal growth factor and other polypeptide mitogens. Annu. Rev. Biochem. 56:881-914.

2. Kasuga, M., F. A. Karlsson, and C. R. Kahn. 1982. Insulin stimulates the phosphorylation of the 95,000 dalton subunit of the insulin receptor. Science (Wash. DC). 215:185-187.

3. Sibley, D. R., J. L. Benovic, M. G. Caron, and R. J. Lefkowitz. 1987. Regulation of transmembrane signaling by receptor phosphorylation. Cell. 48:913-922.

4. Yarden, Y., and A. Ullich. 1988. Growth factor receptor tyrosine kinases. Annu. Rev. Biochem. 57:443-478.

5. Shriner, C. L., and D. L. Brautigan. 1984. Cytosolic protein phosphotyrosine phosphatases from rabbit kidney: purification of two distinct enzymes that bind to $\mathrm{Zn}^{2+}$-iminodiacetate agarose. J. Biol. Chem. 259:11383-11390.

6. Tonks, N. K., C. D. Diltz, and E. H. Fischer. 1988. Purification of the major protein-tyrosine-phosphatases of human placenta. J. Biol. Chem. 263:6722-6730.

7. Roome, J., T. O'Hare, P. F. Pilch, and D. L. Brautigan. 1988. Protein phosphotyrosine phosphatase purified from the particulate fraction of human placenta dephosphorylates insulin and growth-factor receptors. Biochem. J. 256:493-500.

8. Okada, M., K. Owada, and H. Nakagawa. 1986. Phosphotyrosine protein phosphatase in rat brain. Biochem. J. 239:155-162.

9. Jones, S. W., R. L. Erikson, V. M. Ingebritsen, and T. S. Ingebritsen. 1989. Phosphotyrosyl-protein phosphatases. I. Separation of multiple forms from bovine brain and purification of the major form to near homogeneity. J. Biol. Chem. 264:7747-7753. 
10. DeFronzo, R. A., R. Hendler, and D. Simonson. 1983. Insulin-resistance is a prominent feature of insulin-dependent diabetes. Diabetes. 31:795-801.

11. Ginsberg, H., G. Kimmerling, J. M. Olefsky, and G. M. Reaven. 1975. Demonstration of insulin resistance in untreated adultonset diabetic subjects with fasting hyperglycemia. J. Clin. Invest. $55: 454-461$.

12. Kolterman, O. G., J. Insel, M. Saekow, and J. M. Olefsky. 1980. Mechanisms of insulin resistance in human obesity. J. Clin. Invest. 65:1271-1284.

13. Freidenberg, G. R., R. R. Henry, H. K. Klein, D. R. Reichart, and J. M. Olefsky. 1987. Decreased kinase activity of insulin receptors from adipocytes of non-insulin-dependent diabetic subjects. J. Clin. Invest. 79:240-250.

14. Sinha, M. K., W. J. Pories, E. G. Flickinger, D. Meelheim, and J. F. Caro. 1987. Insulin-receptor kinase activity of adipose tissue from morbidly obese humans with and without NIDDM. Diabetes. 36:620-625.

15. Comi, R. J., G. Grunberger, and P. Gorden. 1987. Relationship of insulin binding and insulin-stimulated tyrosine kinase activity is altered in type II diabetes. J. Clin. Invest. 79:453-462.

16. Caro, J. F., M. K. Sinha, S. M. Raju, O. Ittoop, W. J. Pories, E. G. Flickinger, D. Meelheim, and G. L. Dohm. 1987. Insulin receptor kinase in human skeletal muscle from obese subjects with and without noninsulin dependent diabetes. J. Clin. Invest. 79:1330-1337.

17. Caro, J. F., O. Ittoop, W. J. Pories, D. Meelheim, E. G. Flickinger, F. Thomas, M. Jenquin, J. F. Silverman, P. G. Khazanie, and M. K. Sinha. 1986. Studies on the mechanism of insulin resistance in the liver from humans with noninsulin-dependent diabetes. J. Clin. Invest. 78:249-258.

18. Kadowaki, T., M. Kasuga, Y. Akanuma, O. Ezaki, and F. Takaku. 1984. Decreased autophosphorylation of the insulin receptor kinase in streptozotocin-diabetic rats. J. Biol. Chem. 259:1420814216.

19. Burant, C. F., M. K. Treutelaar, and M. G. Buse. 1986. Diabetes-induced functional and structural changes in insulin receptors from rat skeletal muscle. J. Clin. Invest. 77:260-270.

20. Watarai, T., M. Kobayashi, Y. Takata, T. Sasaoka, M. Iwasaki, and Y. Shigeta. 1988. Alteration of insulin-receptor kinase activity by high-fat feeding. Diabetes. 37:1397-1404.

21. Amatruda, J. M., and A. M. Roncone. 1985. Normal hepatic insulin receptor autophosphorylation in nonketotic diabetes mellitus. Biochem. Biophys. Res. Commun. 129:163-170.

22. Blackshear, P. J., R. A. Nemenoff, and J. Avruch. 1984. Characteristics of insulin and epidermal growth factor stimulation of receptor autophosphorylation in detergent extracts of rat liver and transplantable rat hepatomas. Endocrinology. 114:141-152.

23. Kahn, M. N., S. Savoie, J. J. M. Bergeron, and B. I. Posner. 1986. Characterization of rat liver endosomal fractions: in vivo activation of insulin-stimulable receptor kinase in these structures. J. Biol. Chem. 261:8462-8472.

24. Bergmeyer, H. U., and E. Bernt. 1965. Enzymatische Bestimmung von Ketonkorpern in Blut. Enzymol. Biol. Clin. 5:65-76.

25. Williams, L. W., P. M. Tremble, M. F. Lavin, and M. S. Sunday. 1984. Platelet-derived growth factor receptors form a high affinity state in membrane preparations: kinetics and affinity cross-linking studies. J. Biol. Chem. 259:5287-5294.

26. Desbuquois, B., and G. D. Aurbach. 1971. Use of polyethylene glycol to separate free and antibody-bound peptide hormones in radioimmunoassays. J. Clin. Endocrinol. \& Metab. 33:732-738.

27. White, M. F., R. Maron, and C. R. Kahn. 1985. Insulin rapidly stimulates tyrosine phosphorylation of a $M_{\mathrm{r}}=185,000$ protein in intact cells. Nature (Lond.). 318:183-186.

28. Margolis, R. N., S. I. Taylor, D. Seminara, and A. L. Hubbard. 1988. Identification of pp120, an endogenous substrate for the hepatocyte insulin receptor tyrosine kinase, as an integral membrane glycoprotein of the bile canalicular domain. Proc. Natl. Acad. Sci. USA. 85:7256-7259.

29. O'Brien, R., M. D. Houslay, N. P. J. Brindle, G. Milligan, J. Whittaker, and K. Siddle. 1989. Binding to GDP-agarose identifies a novel $60 \mathrm{kDa}$ substrate for the insulin receptor tyrosyl kinase in mouse NIH-3T3 cells expressing high concentrations of the human insulin receptor. Biochem. Biophys. Res. Commun. 158:743-748.

30. Rees-Jones, R. W., and S. I. Taylor. 1985. An endogenous substrate for the insulin receptor-associated tyrosine kinase. J. Biol. Chem. 260:4461-4467.

31. Bernier, M., D. M. Laird, and M. D. Lane. 1987. Insulin-activated tyrosine phosphorylation of a 15-kilodalton protein in intact 3T3-L1 adipocytes. Proc. Natl. Acad. Sci. USA. 84:1844-1848.

32. Fava, R. A., and S. Cohen. 1984. Isolation of a calcium-dependent 35-kilodalton substrate for the epidermal growth factor receptor/ kinase from A-431 cells. J. Biol. Chem. 259:2636-2645.

33. Morrison, D. K., D. R. Kaplan, J. A. Escobedo, U. R. Rapp, T. M. Roberts, and L. T. Williams. 1989. Direct activation of the serine/threonine kinase activity of Raf-1 through tyrosine phosphorylation by the PDGF beta-receptor. Cell. 58:649-657.

34. Wahl, M. I., S. Nishibe, P.-G. Suh, S. G. Rhee, and G. Carpenter. 1989. Epidermal growth factor stimulated tyrosine phosphorylation of phospholipase C-II independently of receptor internalization and extracellular calcium. Proc. Natl. Acad. Sci. USA. 86:1568-1572.

35. Tonks, N. K., C. D. Diltz, and E. H. Fischer. 1988. Characterization of the major protein-tyrosine-phosphatases of human placenta. J. Biol. Chem. 263:6731-6737.

36. Rotenberg, S. A., and D. L. Brautigan. 1987. Membrane protein phosphotyrosine phosphatase in rabbit kidney. Biochem. $J$. 243:747-754.

37. Strout, H. V., P. P. Vicario, R. Saperstein, and E. E. Slater. 1988. A protein phosphotyrosine phosphatase distinct from alkaline phosphatase with activity against the insulin receptor. Biochem. Biophys. Res. Commun. 151:633-640.

38. King, M. J., and G. J. Sale. 1988. Assay of phosphotyrosyl protein phosphatase using synthetic peptide 1142-1153 of the insulin receptor. FEBS (Fed. Eur. Biochem. Soc.). Lett. 237:137-140.

39. Myerovitch, J., J. M. Backer, and C. R. Kahn. 1989. Hepatic phosphotyrosine phosphatase activity and its alterations in diabetic rats. J. Clin. Invest. 84:976-983.

40. Pallen, C. J., G. N. Panayotou, L. Sahlin, and M. D. Waterfield. 1988. Purification of a phosphotyrosine phosphatase that dephosphorylates the epidermal growth factor receptor autophosphorylation sites. Ann. NY Acad. Sci. 551:299-308.

41. Sparks, J. W., and D. L. Brautigan. 1985. Specificity of protein phosphotyrosine phosphatases. J. Biol. Chem. 260:2042-2045.

42. Alemany, S., S. Pelech, C. H. Brierley, and P. Cohen. 1986. The protein phosphatases involved in cellular regulation: evidence that dephosphorylation of glycogen phosphorylase and glycogen synthase in the glycogen and microsomal fractions of rat liver are catalysed by the same enzyme: protein phosphatase-1. Eur. J. Biochem. 156:101110.

43. Tan, A. W. H., and F. Q. Nuttall. 1976. Regulation of synthase phosphatase and phosphorylase phosphatase in rat liver. Biochim. Biophys. Acta. 445:118-130.

44. Bollen, M., and W. Stalmans. 1984. The hepatic defect in glycogen synthesis in chronic diabetes involves the G-component of synthase phosphatase. Biochem. J. 217:427-434. 